Article

\title{
Experimental Investigation of the Ash Deposition Characteristics of Biomass Pretreated by Ash Removal during Co-Combustion with Sub-Bituminous Coal
}

\author{
Dae-Gyun Lee ${ }^{1}$, Min-Jong $\mathrm{Ku}^{1}{ }^{1}$, Kyeong-Ho Kim ${ }^{1}$, Jae-Sung Kim ${ }^{1}$, Seung-Mo Kim ${ }^{2}$ and Chung-Hwan Jeon ${ }^{1,2, *(D)}$ \\ 1 School of Mechanical Engineering, Pusan National University, 2 Busandaehak-ro 63beon-gil, Geumjeong-gu, \\ Busan 46241, Korea; gangoo8@naver.com (D.-G.L.); tbvjalswhd1@naver.com (M.-J.K.); \\ kkh751@pusan.ac.kr (K.-H.K.); e1223kjs@gmail.com (J.-S.K.) \\ 2 Pusan Clean Energy Research Institute, Pusan National University, 2 Busandaehak-ro 63beon-gil, \\ Geumjeong-gu, Busan 46241, Korea; kimsm@pusan.ac.kr \\ * Correspondence: chjeon@pusan.ac.kr; Tel.: +82-51-510-3051; Fax: +82-51-510-5236
}

check for updates

Citation: Lee, D.-G.; Ku, M.-J.; Kim, K.-H.; Kim, J.-S.; Kim, S.-M.; Jeon, C.-H. Experimental Investigation of the Ash Deposition Characteristics of Biomass Pretreated by Ash Removal during Co-Combustion with Sub-Bituminous Coal. Energies 2021, 14, 7391. https://doi.org/10.3390/ en14217391

Academic Editor: Adam Smoliński

Received: 15 September 2021

Accepted: 26 October 2021

Published: 5 November 2021

Publisher's Note: MDPI stays neutral with regard to jurisdictional claims in published maps and institutional affiliations.

Copyright: (c) 2021 by the authors. Licensee MDPI, Basel, Switzerland. This article is an open access article distributed under the terms and conditions of the Creative Commons Attribution (CC BY) license (https:// creativecommons.org/licenses/by/ $4.0 /)$.

\begin{abstract}
Although replacing biomass, (e.g., wood chips and pellets), with thinning wood and herbaceous biomass is eco-friendly and economically advantageous, their direct utilization in plant boilers is associated with ash-related challenges, including slagging and fouling. The aim of this study is to determine the effects of ash removal treatment (ashless biomass (ALB)) in the context of solid fuel power plant boilers. Ash was removed via neutralization of metal ions and carboxylic acids contained in the biomass ash. The ash removal rate of $\mathrm{K}, \mathrm{Na}, \mathrm{Cl}$ was indicated by assessing the total biomass before and after ash removal treatment, via XRF analysis. Co-combustion with sub-bituminous coal and ALB-treated biomass was analyzed using a drop tube furnace and revealed that NOx and SOx values converged converge toward an approximate $10 \mathrm{ppm}$ error, whereas the Unburned Carbon (UBC) data did not exhibit a specific trend. Factors associated with slagging and fouling, (capture efficiency (CE), and energy based growth rate (GRE)) were calculated. All biomass samples without pretreatment exhibited V-shaped variation. Conversely, for ashless biomass (ALB) samples, CE and GRE gradually decreased. Thus, the ALB technique may minimize slagging and fouling in a boiler, thus, reducing internal corrosion associated with ash deposition and enhancing the economic operation of boilers.
\end{abstract}

Keywords: pretreatment; ash removal; alkali; underexploited biomass; thinning wood; kenaf; drop tube furnace; capture efficiency; energy based growth rate

\section{Introduction}

Currently, power generation using biomass, which is a renewable energy source, is attracting significant attention. As such, the exploitation of biomass is being considered worldwide as an avenue for the reduction of environmental emissions. Ongoing projects include the conversion of biomass into electricity and its utilization as an energy source for boilers, with more than 100,000 tons of biomass planned for conversion annually in the United Kingdom. In fact, environmentally friendly power generation systems are set to phase out approximately $85 \%$ and $50 \%$ of SOx and NOx emissions, respectively [1]. In Germany, for example, biodiesel generation from the canola flower is being promoted, and the government is providing subsidies estimated to range between $276-429 €$ / ha for its cultivation [2]. Moreover, various types of biomass have been used to generate electricity. For example, the herbaceous biomass, rice husk, has been widely employed and investigated for this purpose [3]. Poultry litter [4] and agricultural biomass [5] have also been exploited as biofuel worldwide.

However, due to its multiple applications, including that of ordinary wood pellets, biomass utilization poses a potential threat to forest resources. Therefore, replacing biomass, such as wood chips and pellets, with thinning wood and herbaceous biomass, including 
kenaf, offers an alternative eco-friendly and economically advantageous strategy. In the present study, the utilization of underexploited forest biomass is investigated. Thinning of trees in forests is associated with a byproduct that is often incinerated and disposed of as disease and aging limit the areas of application. However, the usage of this poorly exploited resource for power generation will eliminate the disposal cost, expand the biomass uses, and contribute to power generation worldwide. Moreover, considering that certain types of biomass, such as kenaf and discarded rice straw, are obtained from annual crops, a need remains for the identification of stable sources suitable for energy production. Further, studies to develop fuel conversion technology involving mixtures of wood and organic waste biomass are also needed. Therefore, in the present study, the suitability of representative underexploited biomass, such as thinned wood and kenaf, for energy generation was investigated.

However, the direct utilization of these underexploited biomass sources in plant boilers is associated with several challenges. As shown in Figure 1, owing to issues such as slagging and fouling caused by ash in biomass power plants, power outages (annual malfunction rate of up to $50 \%$ ) associated with significant economic losses are frequent [6].

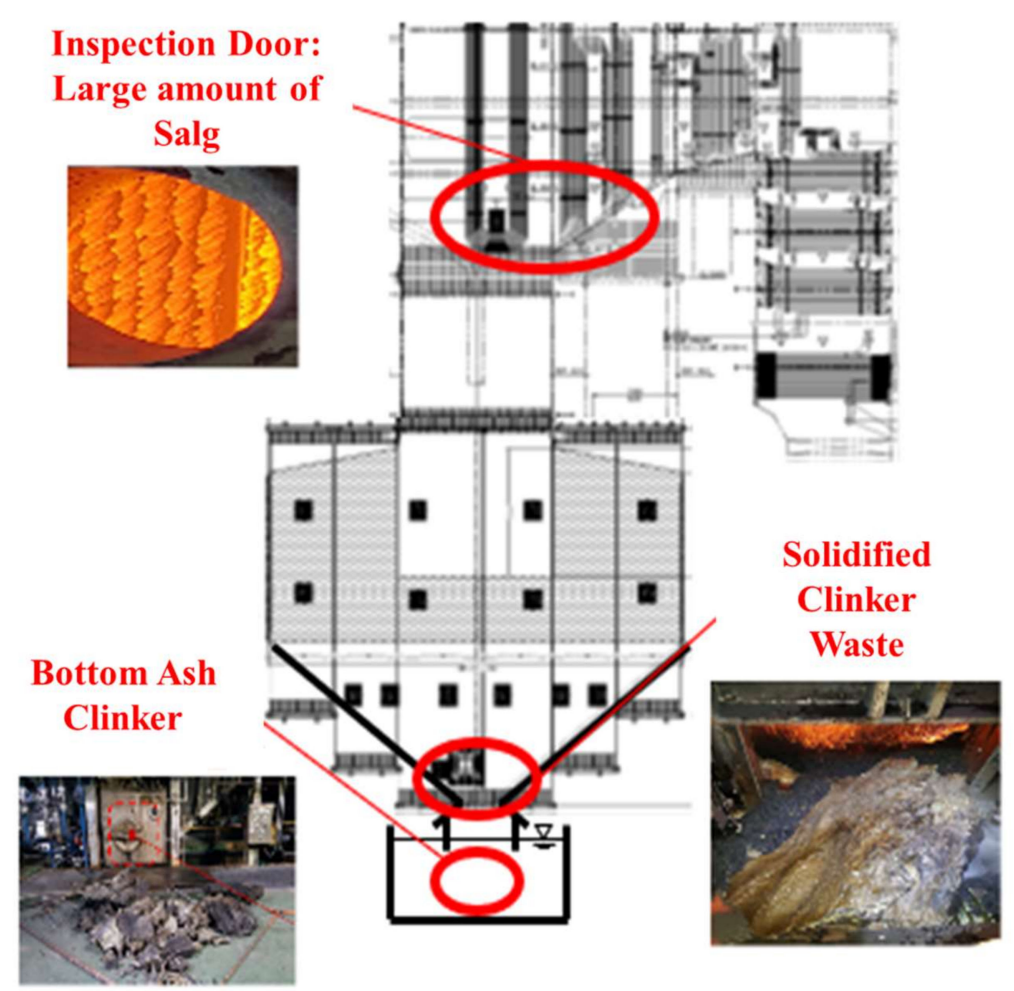

Figure 1. Illustration of clinker and high-temperature corrosion issues associated with biomass fuel.

Owing to significant alkali metal content, biomass sources necessitate pretreatment before utilization in plants. Ash removal is among the utilized pretreatment techniques intended to minimize this issue. Ash from underexploited biomass also contains significant alkali metals (K and $\mathrm{Na}$ ) and chlorine $(\mathrm{Cl})$, and thus, converting these to stable fuels is challenging due to the simultaneous equipment (clinker, slagging, fouling, hot corrosion, etc.) and environmental (ultrafine dust source generation) issues. A previous study investigated the application of low cost agricultural crops, such as wheat straw, rice straw, rice husk, and corn stalk, with specific heat, while addressing combustion-related challenges (gaseous emissions and ash). However, this study primarily focused on the corrosion, $\mathrm{PM} 1.0$ emissions, $\mathrm{HCl}$ and SOx emissions, and ash sintering temperature [7]. Meanwhile, another study examined the potential causes of ash-related slagging and fouling, particularly associated with alkali content in the biofuels. They reported that the alkali contents impact the slagging and agglomeration by causing biomass cofiring [8]. 
Moreover, the corrosion that occurs in the coal-biomass boiler is primarily initiated by $\mathrm{Cl}_{2}$ gaseous alkali chlorides, solid/deposited alkali chlorides, molten alkali chloride, etc., specifically, the alkali and chlorine contents were found to serve as the main inducing factors of corrosion in the boiler system. Hence, in the current study, the alkali metal and chlorine contents were the primary focus when assessing the effects of three different types of biomass, namely, underexploited biomass, including thinned wood (TW) and kenaf, and the reference biomass, wood pellet (WP). The Clean Fuel Research Team in the Korea Institute of Energy Research developed the ashless biomass (ALB) technique that can remove more than $90 \%$ of the $\mathrm{K}, \mathrm{Na}$, and $\mathrm{Cl}$ components from biomass at low temperatures using eco-friendly organic acids. The principle associated with this technique is illustrated in Figure 2 [9]. The acid ion $\mathrm{H}^{+}$can exist in the acidic water and reacts with the alkali content in the biomass via a neutralization reaction. By exploiting this principle, the alkali ash component can be extracted in acidic water. In a biomass power plant, the existing acid treatment, through ion exchange reactions involving carboxylic acids, moisture, and an electrolyte, ultimately results in ash removal while also removing components that generate clinker and promote ash deposition.

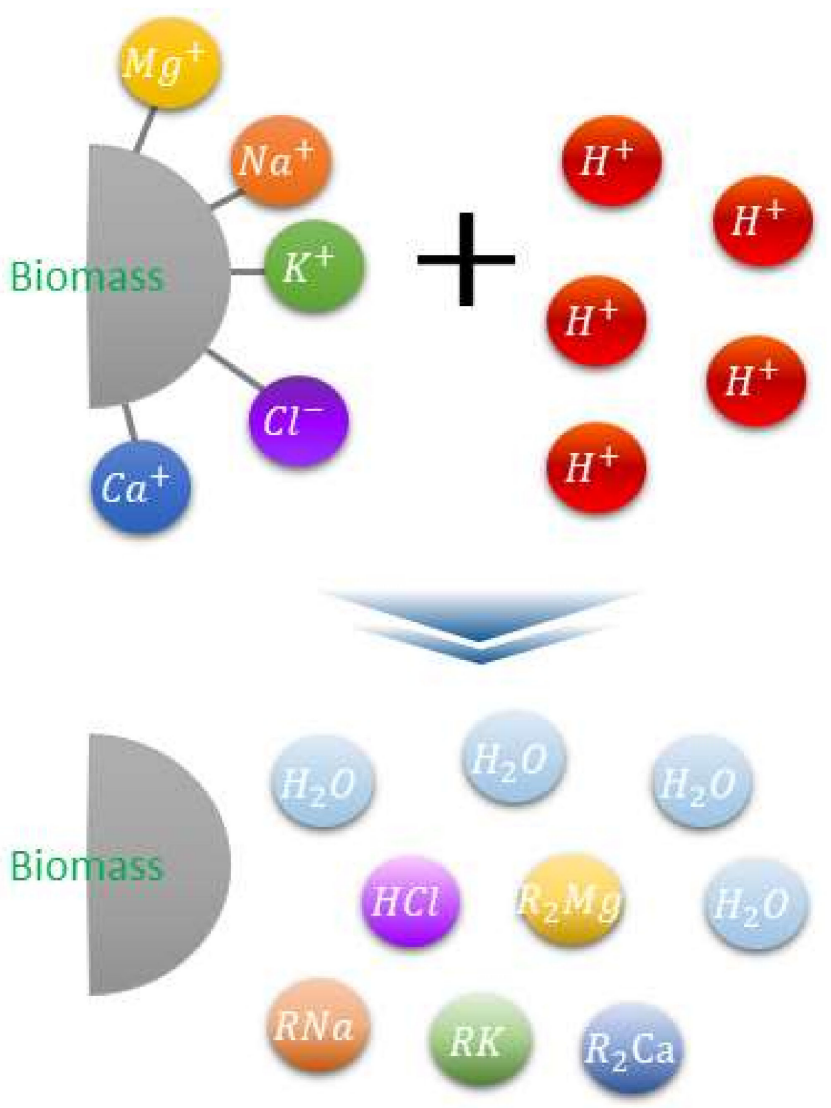

Figure 2. Biomass ash elimination mechanism involving acid treatment [9].

Considering that ash content (alkali, chlorine content) impacts slagging and fouling problems, and is the primary cause of ash deposition [6-8], the ALB technique was employed to remove alkali metals and related components from the biomass in this study. The resulting emission and deposition rates were then analyzed with co-firing bituminous coal and $5 \%$ or $10 \%$ ashless biomass, to target the co-firing biomass in a $500 \mathrm{MW}$ standard pulverized coal boiler. In South Korea coal power plants, PC boilers are used together with biomass, however, the pulverizing system may experience failure in the future due to the issues associated with grindability. Therefore, biomass input is limited to $5 \%$ in pulverized coal boilers. Meanwhile, investigations are also underway to assess the efficacy and associated issues associated with a $10 \%$ biomass input. As such, the current study 
aims to extend these investigations to assess the challenges associated with increasing the biomass mixing ratio to $10 \%$ in PC boilers, as well as the advantages associated with ash removal pretreatment to limit the negative impact of ash deposition.

\section{Experimental}

\subsection{Sample Preparation and Analysis}

In the present study, a lab-scale reactor for extracting ash from biomass was designed and manufactured through consultation with the Korea Institute of Energy Research. Experiments were conducted using a procedure previously reported [9]. The batch ash removal reactor is composed of the reactor, hot water supply tank, and control system. As shown in the reference [9], the reactor contains the raw biomass with a motor that rotates at $100 \mathrm{rpm}$. The hot water supply tanks contain acid water (citric acid). Meanwhile, the temperature of the supply tank, as well as the rotation rate, can be manipulated by the control system.

Although the reactor capacity is approximately $20 \mathrm{~L}$, approximately $2 \mathrm{~kg}$ of biomass and $16 \mathrm{~kg}$ of a citric acid solution ( $\mathrm{pH} 2-7)$ were mixed per batch due to the low density of the biomass. A hydrothermal supply was connected through the side of the reactor, and the reaction temperature $\left(60-120^{\circ} \mathrm{C}\right)$ was controlled by adding steam into the reactor jacket. The mixture in the reactor was stirred at $300 \mathrm{rpm}$ to maximize interactions between the biomass and the acid solution. Ash extraction was achieved as per the protocol presented in Figure 2. The duration of the experiment was fixed at $10 \mathrm{~min}$ to evaluate the potential of rapid ash extraction. After each experiment, the sample mixture was recovered through discharge at the bottom of the reactor, and the solid and liquid components were separated using a $1 \mu \mathrm{m}$ filter paper. The separated solids were washed five times using pure water and subsequently dried in an oven for subsequent use as ALB in a power plant boiler. Proximate and ultimate analyses were performed to determine the calorific value and ash properties, which were used to evaluate ash extraction effects.

Thermal coal was then blended with 5\% and 10\% of the three biomass types, which were representative of underexploited biomass, including TW and kenaf, as well as reference biomass, WP, which is mainly used in power plants in Vietnam. Proximate analysis was conducted using a TGA-701 thermogravimeter (LECO Co., St. Joseph, MI, USA), while ultimate analysis was performed using a TruSpecific analyzer and an SC-432DR sulfur analyzer (LECO). The calorific value of each sample was measured using a Parr 6320EF calorimeter, while ash properties were determined by X-ray fluorescence (XRF) using a Primus II instrument (RIGAKU Co. Akishima, Tokyo, Japan). Analyses were performed according to ASTM standards [10-15], and results from the proximate, ultimate, and calorific value analyses are presented in Table 1.

Table 1. Basic properties (proximate, ultimate value and heating value) of coal and biomass samples.

\begin{tabular}{cccccccc}
\hline Sample & Coal A & WP & Ashless WP & TW & Ashless TW & Kenaf & $\begin{array}{c}\text { Ashless } \\
\text { Kenaf }\end{array}$ \\
\hline Proximate analysis (ad) & & & & & & & \\
\hline Inherent moisture (wt.\%) & 3.31 & 6.60 & 5.82 & 3.28 & 3.30 & 3.38 & 3.08 \\
\hline Ash (wt.\%) & 15.30 & 3.46 & 1.55 & 4.52 & 1.57 & 6.08 & 7.94 \\
\hline Volatile matter (wt.\%) & 33.17 & 69.90 & 74.46 & 71.69 & 74.17 & 72.19 & 76.65 \\
\hline Fixed carbon (wt.\%) & 48.23 & 20.04 & 18.18 & 20.52 & 20.96 & 18.37 & 18.33 \\
\hline C (wt.\%) & Ultimate analysis (DAF) & & & & & \\
\hline H (wt. $\%)$ & 84.63 & 43.03 & 49.30 & 48.68 & 48.95 & 43.55 & 47.30 \\
\hline
\end{tabular}


Table 1. Cont.

\begin{tabular}{cccccccc}
\hline Sample & Coal A & WP & Ashless WP & TW & Ashless TW & Kenaf & $\begin{array}{c}\text { Ashless } \\
\text { Kenaf }\end{array}$ \\
\hline O (wt.\%) & 7.48 & 50.54 & 44.70 & 44.41 & 46.90 & 48.31 & 50.11 \\
\hline N (wt.\%) & 1.76 & 2.88 & 0.30 & 2.59 & 2.52 & 2.86 & 2.86 \\
\hline S (wt.\%) & 0.76 & 0.70 & 0.01 & 0.00 & 0.00 & 0.05 & 0.00 \\
\hline LHV (kcal/kg) & 5593 & 4177 & 3864 & 4566 & 4554 & 4129 & 4411 \\
\hline
\end{tabular}

ad: air dry, DAF: dry ash free, LHV: low heating value.

\subsection{Ash Removal}

Ash properties were characterized by XRF using a Primus II (RIGAKU Co.) instrument according to ASTM standards [15]. The concentrations of chlorine, an element associated with reduction of the ash melting point and promotion of slagging and fouling, were measured by ion chromatography. Ion chromatography involves an ion exchange principle in which a functional group associated with a cation or anion is bonded to a polymer representing the stationary phase of the column. If an unknown substance is injected, the ions of the sample initiate cation or anion substitution and recurrent bond decomposition [16].

The composition of ash from the biomass before and after fuel conversion treatment is presented in Table 2. Evidently, ALB treatment impacted the potential for slagging and fouling. Changes in the concentrations of $\mathrm{K}$ and $\mathrm{Na}$ were evaluated using Equations (1)-(4):

$$
\begin{gathered}
\text { Actual content }[\mathrm{ppm}]=A \operatorname{sh}(w t \%) \times \mathrm{K}^{+}(w t \%) \times 100 \\
\text { Actual } \mathrm{Na}^{+} \text {content }[\mathrm{ppm}]=A \operatorname{sh}(w t \%) \times N a^{+}(w t \%) \times 100 \\
\mathrm{~K}^{+} \text {removal efficiency }=100-\frac{A \operatorname{sh}{ }_{A}(w t \%) \times K^{+}{ }_{A}(w t \%)}{A s h_{\text {raw }}(w t \%) \times K^{+}{ }_{\text {raw }}(w t \%)} \times 100 \\
\mathrm{Na}^{+} \text {removal efficiency }=100-\frac{A \sin A(w t \%) \times N a^{+}{ }_{A}(w t \%)}{A s h_{\text {raw }}(w t \%) \times N a^{+} \text {raw }(w t \%)} \times 100
\end{gathered}
$$

where $A s h_{A}$ is the ashless biomass ash component, $A s h_{\text {raw }}$ is the raw biomass ash compo-

\begin{tabular}{|c|c|c|c|c|c|c|c|c|c|}
\hline Sample (wt.\%) & $\mathrm{SiO}_{2}$ & $\mathrm{Al}_{2} \mathrm{O}_{3}$ & $\mathrm{Fe}_{2} \mathrm{O}_{3}$ & $\mathrm{CaO}$ & $\mathrm{MgO}$ & $\mathrm{Na}_{2} \mathrm{O}$ & $\mathrm{K}_{2} \mathrm{O}$ & Others & $\mathrm{Cl}^{-}$ \\
\hline Coal A & 65.45 & 23.97 & 4.87 & 1.07 & 0.7 & 0.27 & 1.24 & 2.44 & N.D \\
\hline WP & 24.62 & 3.87 & 3.04 & 24.92 & 5.52 & 1.27 & 13.25 & 23.52 & 0.13 \\
\hline Ashless WP & 32.69 & 4.97 & 3.86 & 27.75 & 2.72 & 1.36 & 4.85 & 21.8 & 0.04 \\
\hline TW & 46.55 & 10.60 & 3.66 & 19.48 & 3.45 & 0.74 & 8.36 & 7.16 & 0.03 \\
\hline Ashless TW & 72.56 & 9.37 & 0.70 & 11.23 & 0.00 & 0.00 & 3.06 & 3.08 & 0.01 \\
\hline Kenaf & 6.71 & 2.08 & 0.82 & 13.75 & 8.94 & 0.35 & 33.67 & 33.68 & 3.85 \\
\hline Ashless kenaf & 20.71 & 4.79 & 4.75 & 23.97 & 6.37 & 1.00 & 9.73 & 29.06 & 0.03 \\
\hline
\end{tabular}
nent, $K_{A}$ is the ashless biomass $K^{+}$content, $K_{\text {raw }}$ is the raw biomass $K^{+}$content, and $\mathrm{Na}$ is associated with the same parameters.

Table 2. Ash composition rate of coal and raw biomass om ALB samples.

N.D: not detected.

\subsection{Gas Emission and Unburned Carbon Analysis}

Gases produced using the drop tube furnace (DTF), which reflect the actual boiler, such as NOx and SOx, as well as the unburned carbon (UBC), were determined. Experiments were performed in triplicate. Components in the exhaust gas at the rear end of the DTF were analyzed every second, and the data were stored in a laptop wirelessly connected to the analyzer. The average data of the exhaust gas components for each sample type 
were associated with a semi-normal state of the combustion reaction shown in Figure 3. The results obtained vary based on the experimental conditions; in particular, the NOx concentration significantly changed depending on the $\mathrm{CO}_{2}$ and $\mathrm{O}_{2}$ in the exhaust gas. In general, the NOx concentration can be obtained based on a reference $\mathrm{O}_{2}$ concentration of $6 \%$. The conversion can be performed using Equation (5):

$$
N O_{x,} @ 6 \% \mathrm{O}_{2}=\frac{21 \%-\mathrm{O}_{2, \text { measurment }}[\%]}{21 \%-6 \%} \times N O_{x, \text { measurement }}
$$

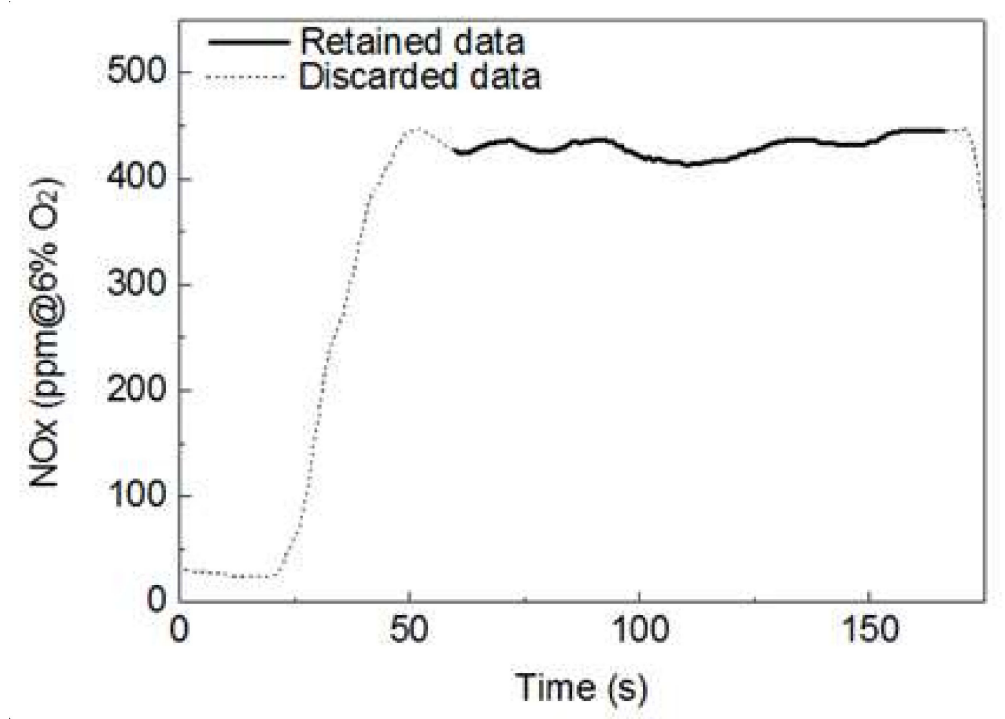

Figure 3. Plot showing an example of the processing of data used for analysis of the exhaust gas.

Regarding the UBC, owing to the low collectible char or ash relative to the initial fuel utilized, this component was determined using the ash tracer method. This method enables the comparison of the ash content associated with char after combustion to that of the fuel before combustion. The burnout or UBC of the fuel is then determined based on a proportionality relationship as expressed in Equation (6) [17]:

$$
U B C(\%)=\frac{A_{0}\left(100-A_{\text {char }}\right)}{\left(A_{\text {char }}\left(1-A_{0}\right)\right.} \times 100
$$

where $A_{0}$ is the ash content of the pre-combustion sample and $A_{\text {char }}$ is the ash content of the char after combustion.

\subsection{Ash Deposition Rate Experiment}

To adequately understand slagging and fouling, which are phenomena commonly associated with ash deposition, elucidation of the ash deposition mechanism is necessary. A proposed mechanism for ash generation during coal combustion is displayed in Figure 4. Exposure of coal to the high-temperature boiler environment is accompanied by the volatilization of some components, while others produce fine particles, and the rest remain as char particles. If the temperature drops, certain volatilized inorganic materials revert to fine particles through nucleation, followed by fusion to regenerate ash. Meanwhile, a portion of the inorganic particles in the char are liberated through char combustion. Although the ash is a component of a particle, as described in Figure 4, its generation is associated with varying pathways. Consequently, ash samples are characterized by diverse particle size distributions after combustion. This generation path is essentially controlled by the environment the coal is exposed to during the carbonization process, the carbonization duration, and the source material of the coal. In addition, the generation pathway can be influenced by the temperature and associated parameters of the combustion system. Consequently, most studies on slagging and fouling have focused on the mineral properties 
of coal, particularly the composition, distribution, and size of ash components, as well as their structural properties. Existing slagging and fouling models are based on empirical relationships derived from experimentally measured physicochemical phenomena. Therefore, all variables are associated with the ash component as an input. Thus, the prediction of slagging and fouling must involve a precise and quantitative analysis of the coal, including the identification and classification of inorganic minerals as well as their properties, such as the size, density, and melting point. Slagging and fouling in a boiler often commence with deposition. The melting and formation of sintered layers by deposited particles is termed slagging, whereas condensation of particle batches on a relatively low-temperature surface to produce layers is known as fouling. Therefore, these phenomena are distinct or coexist depending on the temperature and related conditions. The mechanism of deposition on the walls of a combustion furnace is illustrated in Figure 4. Deposition on a clean surface begins with the collision of particles circulating in the reactor, and large particles are deposited by inertial impact, while small particles are added on the inner walls at lower temperatures through thermophoresis, eddy impact, and diffusion. In addition, some inorganic ions associated with gases also condense and are deposited on the inner walls of the furnace. Deposition may also arise from reactions between solids and gases $[18,19]$, and the ash deposition rate can be expressed as shown in Equation (7) [20]:

$$
\frac{d m}{d t}=I \cdot C E+E+T+C+R
$$

where $I$ is the inertial impaction rate, $C E$ represents the capture efficiency, $E$ denotes the eddy impaction, $T$ designates the thermophoretic deposition rate, $C$ refers to the condensation rate, and $R$ is the reaction rate.

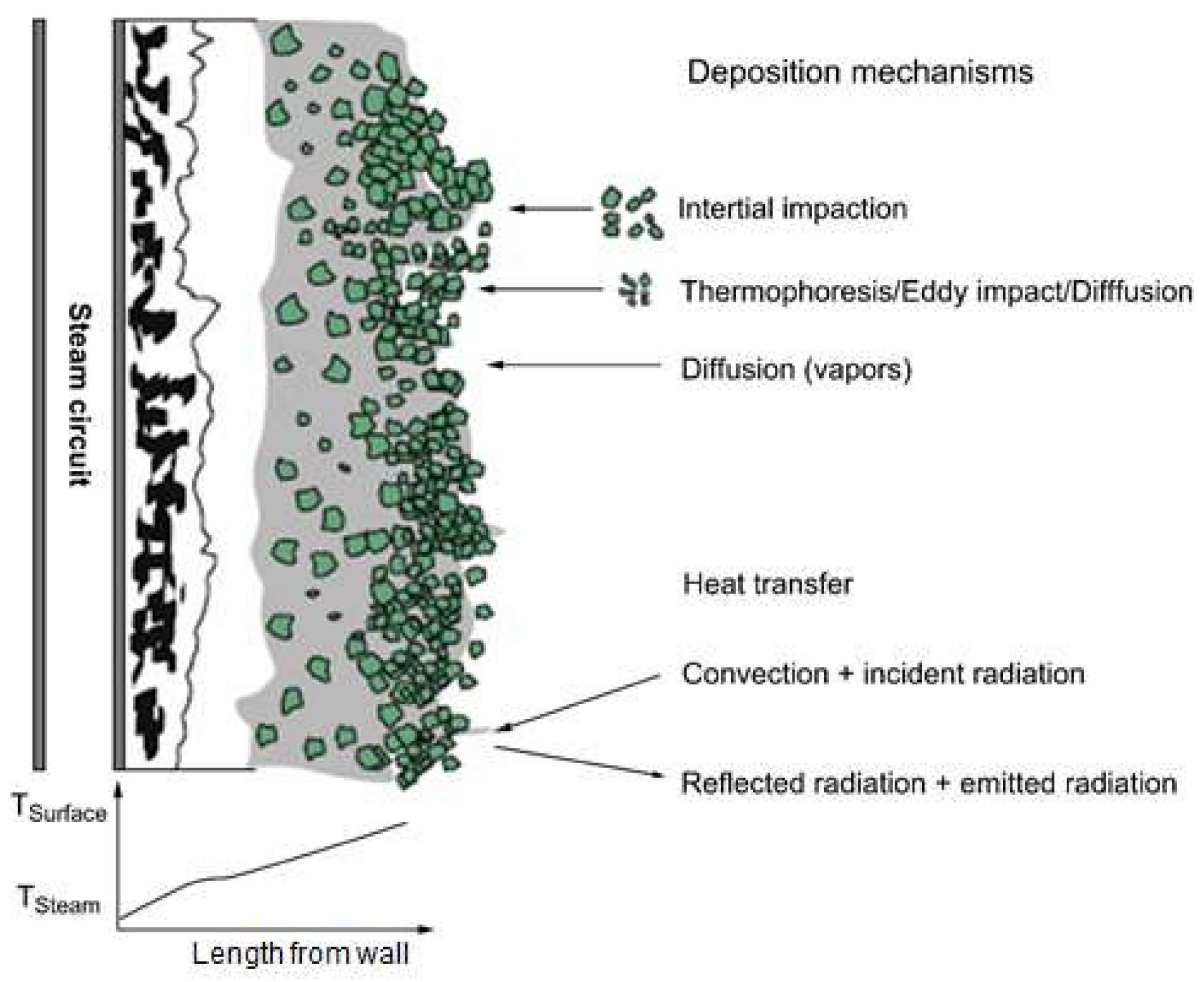

Figure 4. Conceptual illustration of mechanisms of ash deposition on the walls of a furnace [18].

These parameters are further described as follows: during the inertial impact (I), particles are characterized by sufficient momentum to pass through the surrounding fluid flow region and collide with obstacles such as tubes. This represents the dominant mechanism for the rapid accumulation of ash in superheater tubes. The capture efficiency (CE) is the extent to which particles remain on a surface after the collision through inertial impact. 
The eddy impaction (E) is a phenomenon during which fine ash particles are deposited on the surfaces of particles as a function of turbulence. This involves particles unaffected by inertial impaction, and commonly involves other mechanisms. Thermophoresis (T) refers to the movement of particles associated with rapid temperature gradients. This generally affects fine particles associated with a low-temperature range transport. Batch precipitation in cooled superheater tubes is a prime example of ash precipitation associated with this mechanism. Inertial impact usually occurs only on the upstream side of the tube, whereas batch precipitation caused by thermophoresis is uniformly present throughout the tube. During condensation (C), vaporized inorganic particles (mainly alkalides) are formed by agglomeration on a low-temperature surface. The relatively low temperature around a cooled tube promotes the condensation of some gas components, which causes precipitation on the tube. The generation is controlled by the gas components and the temperature. Reactions (R) between solids and gases directly affect the ash deposition rate and the characteristics of the ash. Principal reactions associated with ash deposition include sulfation, alkali absorption, and oxidation. These reactions are governed by the concentration gradients of species present.

Owing to its close association with the deposition rate, the CE is the focus of the present study. Experiments were conducted using a DTF, which is suitable for simulating a solid fuel boiler, and its components are displayed in Figure 5. Many studies on coal combustion have been conducted using the DTF as it can be operated at different temperatures and pressures. The DTF comprises an injection unit through which samples and gases are introduced, a reaction unit for combustion, and a collection unit for the collection of samples and analysis of emissions. The fuel and reaction gases are introduced through the injection unit, and these gases include a carrier gas associated with the fuel, as well as a the main reaction gas injected near the tube transporting the carrier gas. The fuel and reaction gas quantities can be adjusted using a feeder system, which includes a syringe pump, a flow rate controller, and a flow meter. The reaction unit is where the interactions between the fuel and reactive gas occur. A constant temperature field was generated in the reaction unit by adjusting the temperature of the $\mathrm{SiC}$ heater using a temperature controller; the temperature can reach $1300{ }^{\circ} \mathrm{C}$ in the DTF. The collection unit enables the recovery of the sample after the experiment. To prevent further oxidation reactions in the char, cool water is passed through the collection probe to lower its temperature. The gases and solids can then be separated using the lower cyclone. In addition, by changing the probe of the collecting unit, the ash deposition can be measured, which was the focus of the current study.

The ash deposition experiment was performed using the DTF equipped with a probe for ash deposition (Figure 5). The probe contained a hollow cylinder and was maintained at a low temperature using circulating water, to prevent the melting associated with the high temperature used in the experiment. The hollow cylinder was designed to adequately separate the ash after deposition so that the deposited ash could be collected. The experimental conditions included a furnace temperature of $1300{ }^{\circ} \mathrm{C}$ and a sample feeding rate of $0.16 \mathrm{~g} / \mathrm{min}$ to attain $10 \mathrm{~g}$. These conditions impact the ash deposition, especially the gas temperature, which is favorable for slagging in the radiative zone, and this is consistent with previous studies [21]. The probe was tested approximately $5 \mathrm{~cm}$ from the bottom in the reaction zone, representing a position at which particles are characterized by low carbon contents due to the impact of combustion and ambient temperature. The internal combustion conditions were approximately 1.16 times higher relative to the excess air volume, which was similar to conditions in a boiler. Based on the feeding rate of $0.16 \mathrm{~g} / \mathrm{min}$, approximately $1 \mathrm{~h}$ was required to introduce $10 \mathrm{~g}$ of each sample. 

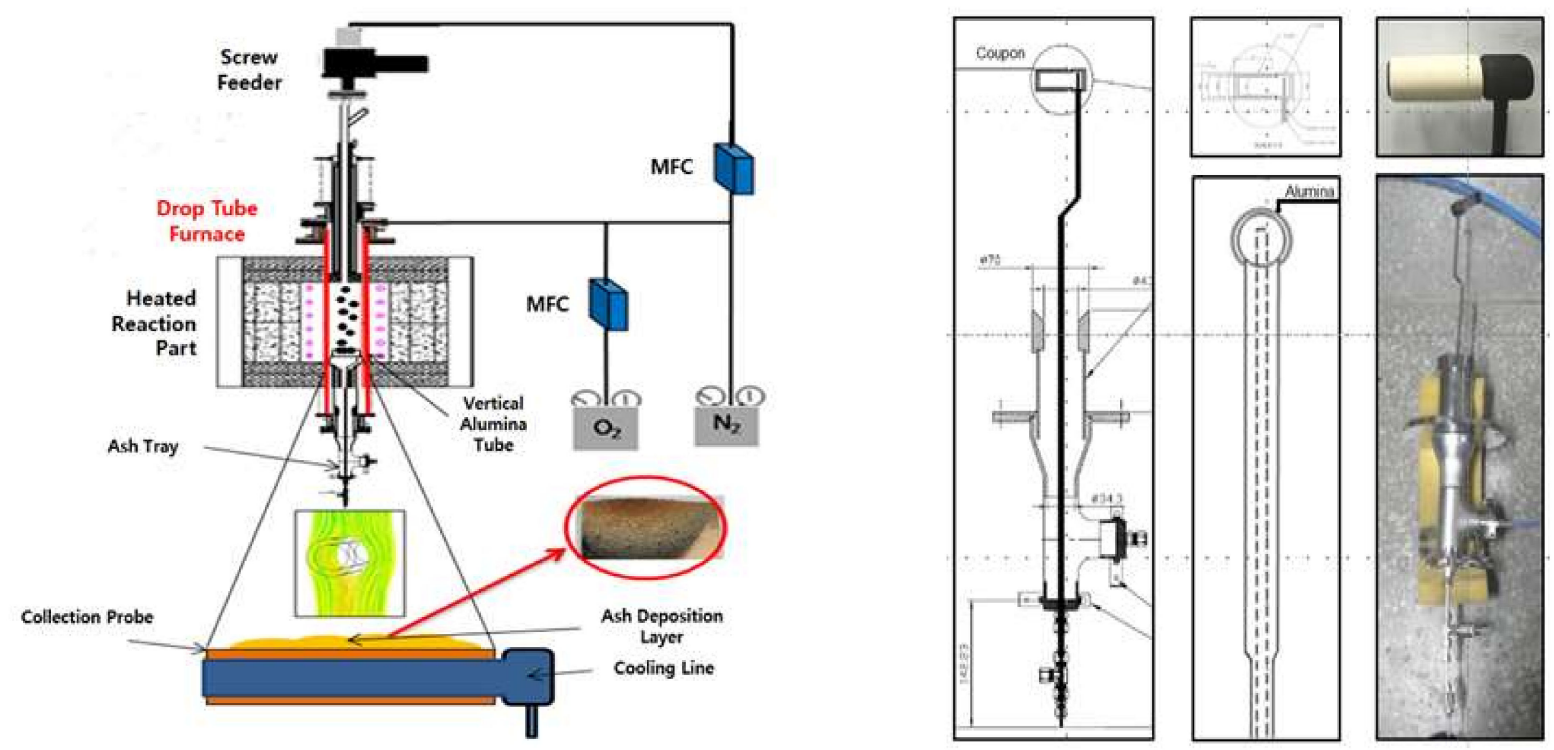

Figure 5. Schematic representation of the components of a drop tube furnace (DTF) connected to an ash deposition probe [21].

Ash deposition was evaluated based on the masses obtained after the DTF experiments. These measurements were normalized to accommodate differences associated with the samples, and were compared using the following indexes:

The CE [22] was calculated by dividing the mass of adhered particles by the mass of particles that passed through the projected surface area of the probe (Equation (8)). Thus, the $\mathrm{CE}$ indicates the fraction of the deposited ash and highlights the tendency of particles to adhere without considering the ash generation potential of a sample.

$$
C E=\frac{m_{\text {Dep }}}{m_{\text {ash }} \frac{A_{\text {coupon }}}{A_{\text {reactor }}}} \times 100\left[\% \mathrm{og}_{\text {Dep }} / \mathrm{kg}_{\text {Ash }}\right]
$$

Alternatively, this can be expressed using measured parameters as in Equation (9)

$$
C E=\frac{m_{\text {Dep }}}{m_{\text {Fuel }}\left(\frac{A^{P}}{100}\right)\left(\frac{A_{\text {coupon }}}{A_{\text {reactor }}}\right)} \times 100\left[\% \mathrm{~kg}_{\text {Dep }} / k_{g_{\text {Ash }}}\right]
$$

where $m_{\text {Dep }}, m_{A s h}$, and $m_{\text {Fuel }}$ represent the mass of ash deposited, the mass of ash passing through the reaction unit, and the mass of sample utilized in the experiment, respectively. $A_{\text {coupon }}$ is the projected area of the hollow cylinder, and $A_{\text {reactor }}$ is the cross-sectional area of the DTF, while $A_{P}$ is the amount of raw ash in the sample. Therefore, the $C E$ is useful for determining the fraction of particles associated with adhesion. However, this index neglects other effects associated with the boiler. First, the mineral matter quantity significantly affects the ash growth rate during deposition. Second, the coal quantity utilized to produce the desired energy depends on its calorific value. These effects are encompassed in the energy based growth rate (GRE), which is defined as the growth rate of ash deposition per calorie during coal combustion and can be expressed with Equation (10) [23].

$$
\frac{m_{\text {Dep }}}{L H V \cdot m_{\text {Feul }}}\left[g_{\text {Dep }} / M J \text { or }\left(g_{\text {Dep }} / s\right) / M W\right]
$$

Based on Equation (10), the CE and GRE can be related through Equation (11).

$$
G R E=\frac{C E \cdot 10^{3}}{100} \times\left(\frac{A^{P}}{100}\right) \times\left(\frac{1}{L H V}\right) \times\left(\frac{A_{\text {coupon }}}{A_{\text {reactor }}}\right)\left[g_{\text {Dep }} / M\right]
$$


Better prediction of slagging can be achieved by using an index related to the material based on energy rather than the ash properties. This suggests that the GRE can serve as an important practical index. Nevertheless, the CE provides information on specific aspects of the deposition.

\section{Results and Discussion}

\subsection{Ash Removal Associated with the Pretreatment}

Changes in the $\mathrm{K}_{2} \mathrm{O}, \mathrm{Na}_{2} \mathrm{O}$, and $\mathrm{Cl}$ concentrations of the biomass types associated with the ALB treatment are presented in Figures 6-8, respectively. The WP, which was introduced for comparison, displays removal efficiencies of $84 \%, 78 \%$, and $82 \%$ for $\mathrm{K}, \mathrm{Na}$, and $\mathrm{Cl}$, respectively, after ALB treatment. The unexploited TW shows removal efficiencies of $87 \%, 100 \%$, and $9 \%$ for $\mathrm{K}, \mathrm{Na}$, and $\mathrm{Cl}$, respectively. Relatedly, kenaf was associated with $\mathrm{K}, \mathrm{Na}$, and $\mathrm{Cl}$ removal efficiencies of $90 \%, 9 \%$, and $70 \%$, respectively. In kenaf, $\mathrm{K}$ was preferentially extracted relative to $\mathrm{Na}$ due to its higher reactivity.

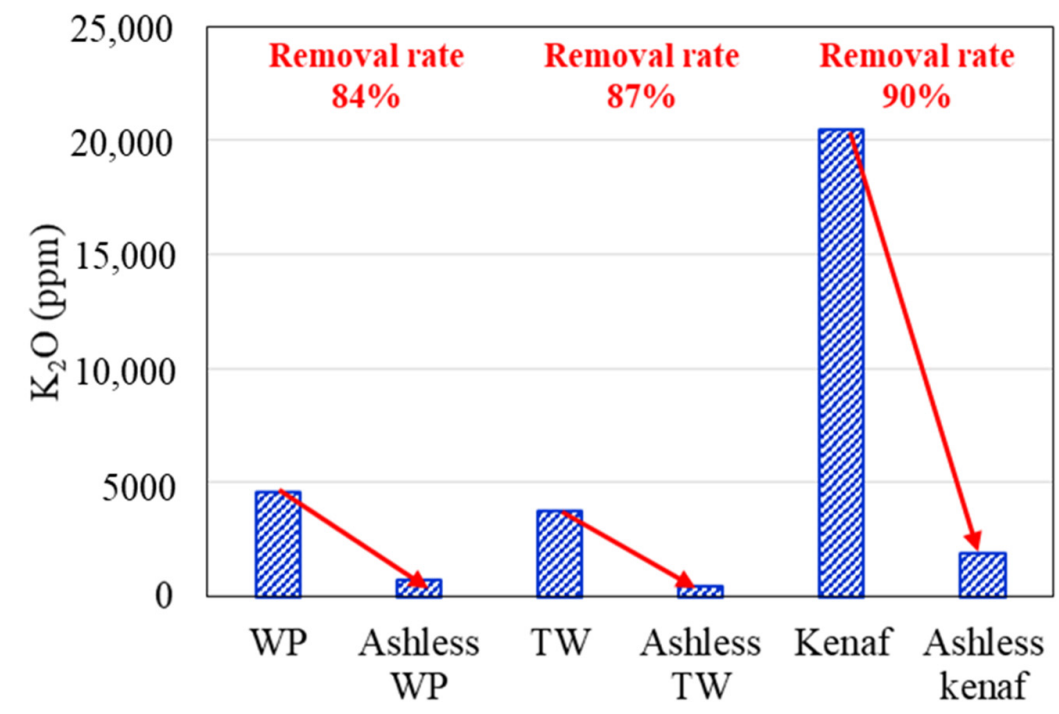

Figure 6. $\mathrm{K}_{2} \mathrm{O}$ contents of three biomass types before and after the ALB treatment.

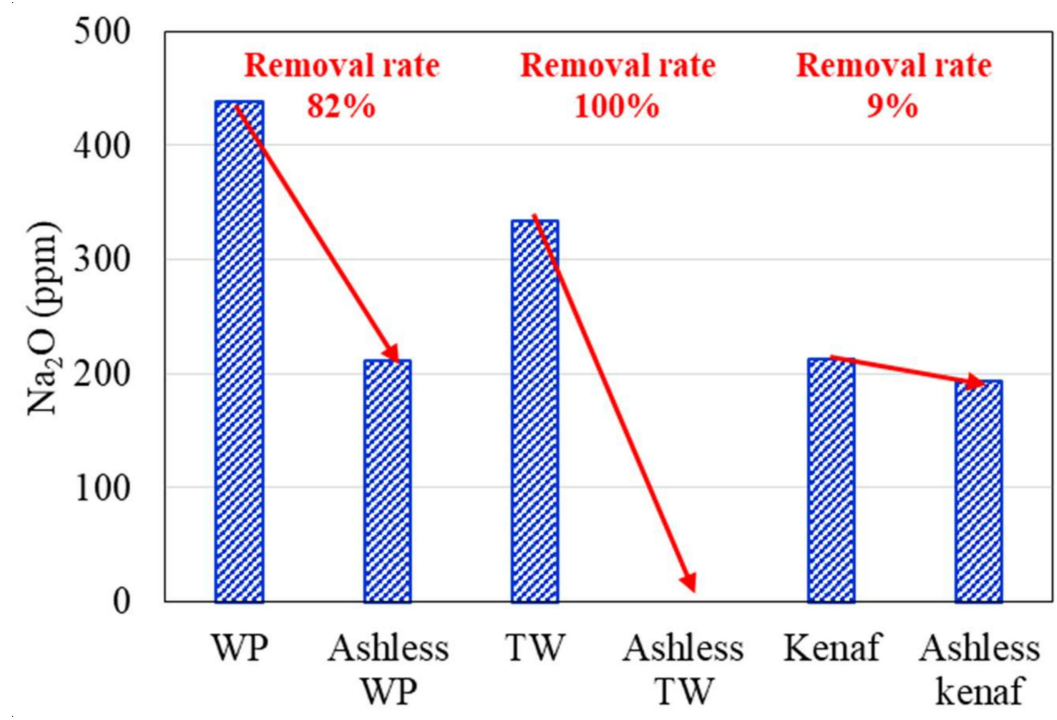

Figure 7. $\mathrm{Na}_{2} \mathrm{O}$ contents of three biomass types before and after the ALB treatment. 


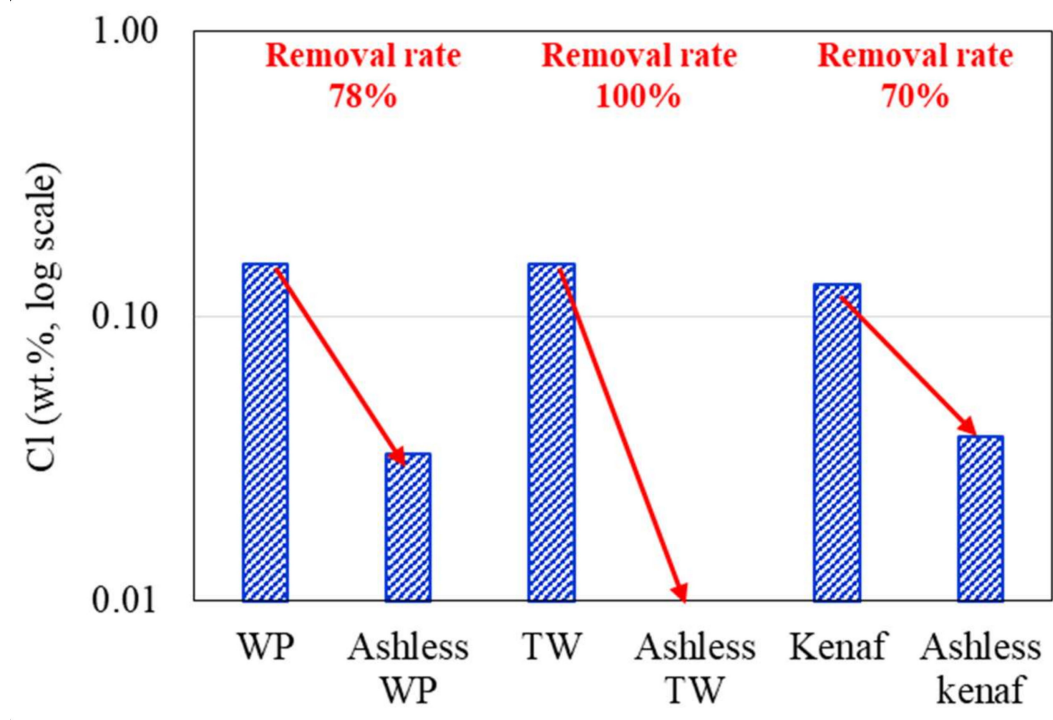

Figure 8. $\mathrm{Cl}$ contents of the biomass types before and after ALB treatment.

\subsection{Gases and UBC Associated with the ALB Co-Combustion}

Experiments were conducted using coal and coal mixtures containing $5 \%$ and $10 \%$ raw and ALB biomass. The generated gas composition and UBC data are presented in Table 3. Overall, after mixing coal and biomass, the NOx and UBC tended to decrease, while the SOx slightly increased. However, in most cases, the SOx values of approximately $30-50 \mathrm{ppm}$ are relatively lower than those produced from bituminous and sub-bituminous coals [24,25]. In all cases, the NOx and SOx values converge toward an error of approximately $10 \mathrm{ppm}$, whereas the UBC data shows no trend. These characteristics are attributed to the removal of alkali metal ions through the ALB treatment, without any influence of the combustion [26].

Table 3. Summary of the gas and UBC concentration in different sample blends.

\begin{tabular}{cccc}
\hline Sample & NOx (ppm) & SOx (ppm) & UBC (\%) \\
\hline Coal A & 102.85 & 27.72 & 40.43 \\
\hline Coal A + WP (5\%) & 87.14 & 40.51 & 28.18 \\
\hline Coal A + WP $(10 \%)$ & 95.64 & 38.27 & 37.53 \\
\hline Coal A + Ashless WP (5\%) & 96.34 & 39.32 & 20.04 \\
\hline Coal A + Ashless WP $(10 \%)$ & 93.73 & 42.25 & 15.45 \\
\hline Coal A + TW (5\%) & 84.15 & 30.64 & 27.92 \\
\hline Coal A + TW $(10 \%)$ & 84.89 & 35.74 & 27.24 \\
\hline Coal A + Ashless TW $(5 \%)$ & 91.03 & 44.81 & 36.16 \\
\hline Coal A + Ashless TW $(10 \%)$ & 93.17 & 39.54 & 27.63 \\
\hline Coal A + Kenaf $(5 \%)$ & 88.87 & 52.23 & 25.50 \\
\hline Coal A + Kenaf $(10 \%)$ & 82.69 & 40.22 & 39.18 \\
\hline Coal A + Ashless Kenaf $(5 \%)$ & 84.75 & 39.21 & 38.51 \\
\hline Coal A + Ashless Kenaf $(10 \%)$ & 90.86 & 47.44 & \\
\hline
\end{tabular}

\subsection{Ash Deposition Rate after the ALB Cofiring}

DTF experiments were conducted to compare the ash deposition produced by coal mixed with raw and ashless biomass. In general, the ash component of coal is divided into indexes to suppress clinker generation, and the effect on clinker development is predicted and evaluated based on short or mixed coal. First, the properties of the raw materials were analyzed to predict the clinker development for each sample. Deposition characteristics 
of samples containing $5 \%$ and $10 \%$ of each biomass type were compared using the DTF experiment data. The feeding amount and deposited mass of ash are shown in Table 4. Also, CE and GRE were calculated to evaluate the ash deposition of various fuels, and the results are displayed in Figure 9, Figure 10, Figure 11. The CE involves the deposition associated with the ash in coal before combustion, while the GRE reflects the ash linked to the energy supplied.

Table 4. Feed and deposited ash mass for coal and coal mixtures.

\begin{tabular}{ccc}
\hline Sample & $\begin{array}{c}\text { Total Feed } \\
(\mathbf{g})\end{array}$ & $\begin{array}{c}\text { Deposited Mass } \\
(\mathbf{g})\end{array}$ \\
\hline Coal A & 10 & 0.134 \\
\hline Coal A + WP (5\%) & 10 & 0.104 \\
\hline Coal A + WP (10\%) & 10 & 0.125 \\
\hline Coal A + Ashless WP (5\%) & 10 & 0.119 \\
\hline Coal A + Ashless WP (10\%) & 10 & 0.109 \\
\hline Coal A + TW (5\%) & 10 & 0.090 \\
\hline Coal A + TW (10\%) & 10 & 0.125 \\
\hline Coal A + Ashless TW (5\%) & 10 & 0.110 \\
\hline Coal A + Ashless TW (10\%) & 10 & 0.099 \\
\hline Coal A + Kenaf (5\%) & 10 & 0.128 \\
\hline Coal A + Kenaf (10\%) & 10 & 0.135 \\
\hline Coal A + Ashless Kenaf $(5 \%)$ & 10 & 0.098 \\
\hline Coal A + Ashless Kenaf $(10 \%)$ & 10 & 0.116 \\
\hline
\end{tabular}

$\square \mathrm{CE} \otimes \mathrm{GRE}$

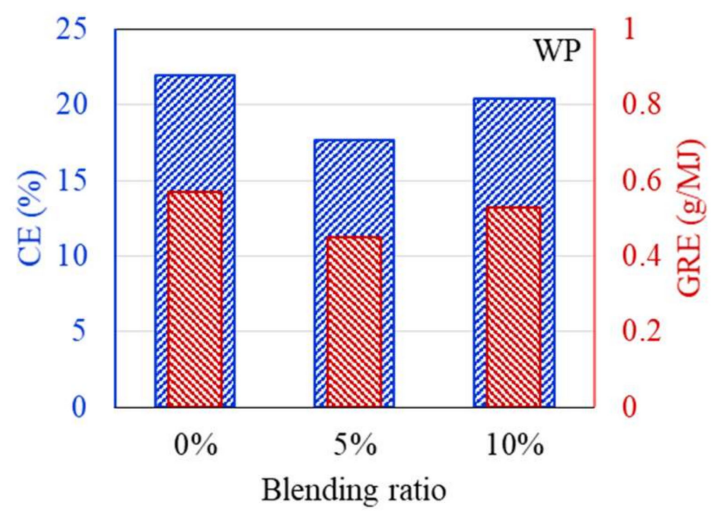

口CE $\otimes G R E$

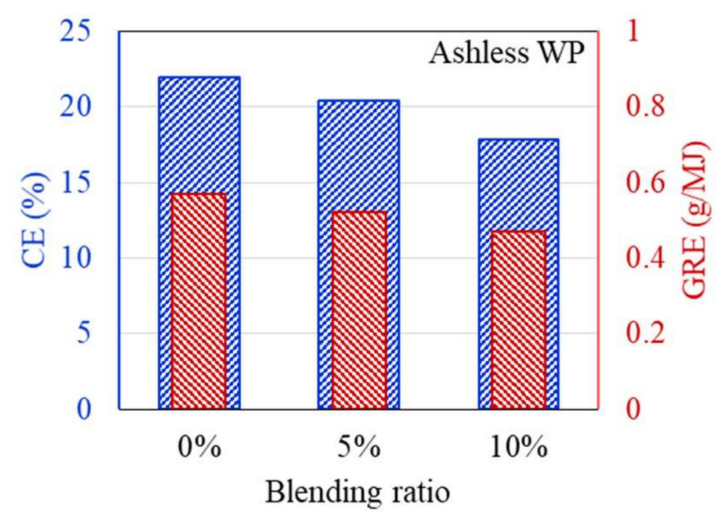

Figure 9. CE and GRE for cofiring different blends of the WP (left) and ashless WP (right).

According to the DTF deposition experiments, the ash, CE, and GRE for the six coalbiomass mixtures tended to decrease. However, the ash deposition associated with the TW increased from $0.09 \mathrm{~g}$ when mixed with $5 \%$ to $0.125 \mathrm{~g}$ when mixed with $10 \%$, while the CE correspondingly increased from $15.24 \%$ to $20.42 \%$. Conversely, the ash deposition for the ashless TW decreased from $0.11 \mathrm{~g}$ for the $5 \%$ mixture to $0.099 \mathrm{~g}$ for the $10 \%$ mixture, and these changes were confirmed by the $\mathrm{CE}$, while the adhesion ratio decreased to $16.87 \%$. Regarding the ashless kenaf, the deposited ash increased from $0.098 \mathrm{~g}$ for $5 \%$ to $0.116 \mathrm{~g}$ for $10 \%$ mixing, which is comparable to the 0.128 g produced by mixing with $5 \%$ of the raw kenaf. However, a comparison of the ash deposition associated with the raw coal and the mixtures revealed the largest decrease in the ash, CE, and GRE, indicating that the coal impacted the ash deposition potential of each sample. Collectively, these findings indicate 
that for the raw biomass, as the proportion of mixing increased, more ash was deposited, and the CE and GRE increased. However, for the ashless biomass, the ash deposition, CE, and GRE decreased as the proportion of mixing increased. Therefore, mixing with ashless biomass seems to decrease the ash deposited by samples. The ashless biomass quantity, however, decreased as the ashless biomass proportion in the mixture increased. This is beneficial in relation to clinker generation, which occurs due to mixing in coal boilers, and causes numerous issues.
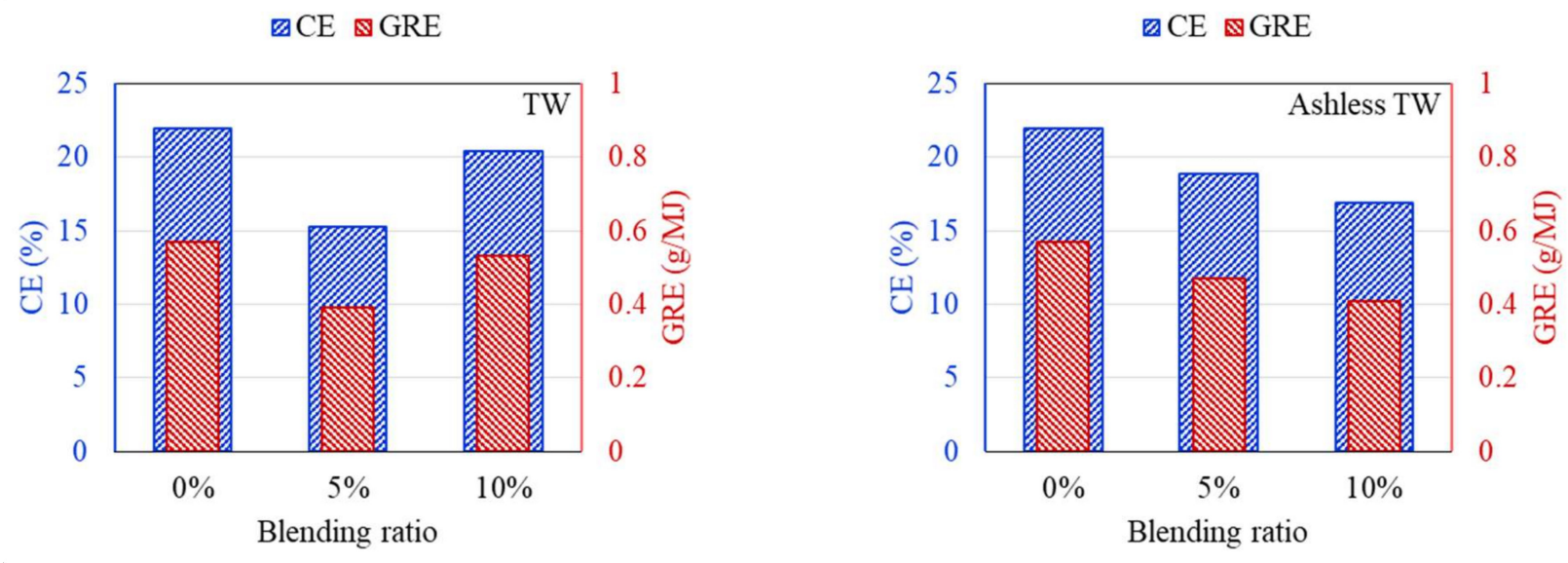

Figure 10. CE and GRE for cofiring different blends of the TW (left) and ashless TW (right).
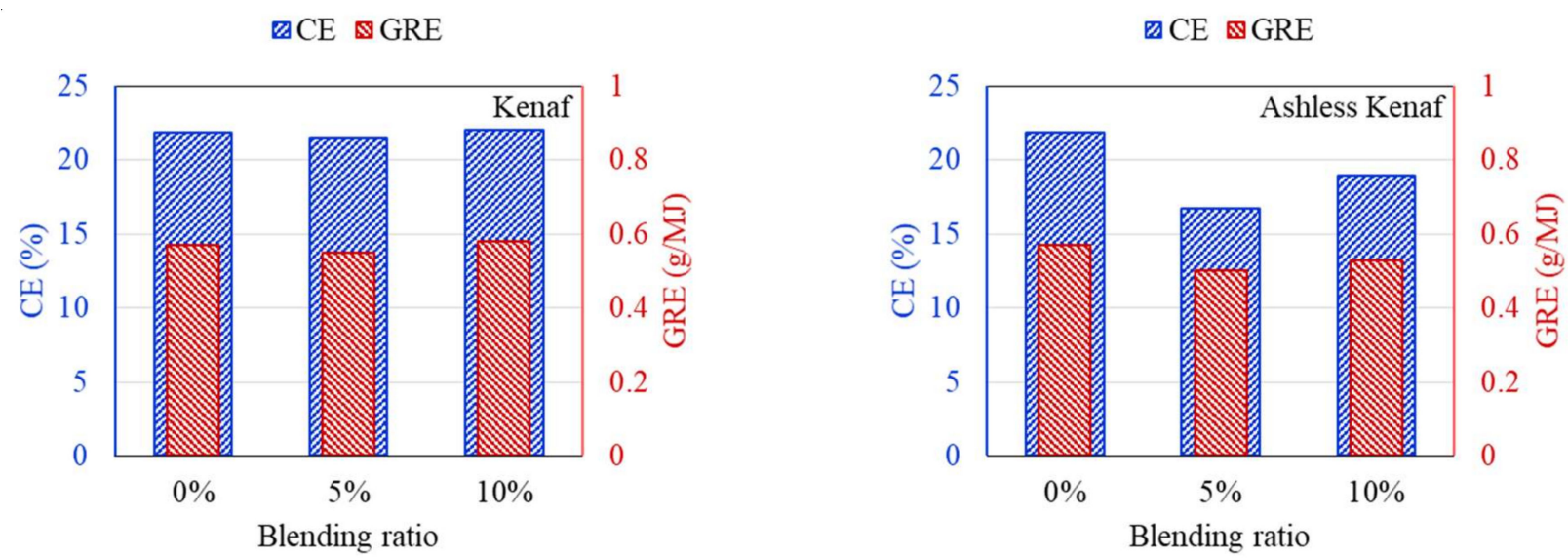

Figure 11. CE and GRE of cofiring different blends of the kenaf (left) and ashless kenaf (right).

\subsection{Effect of Ash Removal Pretreatment on the Boiler}

According to the results shown in Figure 7, Figure 8, Figure 9, all biomass samples without pretreatment exhibit a V-shaped variation. This pattern is consistent with that reported for the CE and GRE in a previous study [21]. Moreover, studies have also revealed that this trend does not apply to samples with low ash content [27]. However, if biomass associated with high ash is utilized, a similar trend is observed [28]. Therefore, the CE and GRE data generated in the present study confirmed the benefit of the ash removal treatment on ash deposition. Regarding the raw biomass associated with high ash, further co-combustion after generation of the V-shaped pattern can elevate the ash in the boiler due to an increase in alkali metals in the sample. Conversely, for the ALB, which involves ash removal, the total alkali decreases. Therefore, the ALB technique exhibits the potential for minimizing slagging and fouling in a boiler. Further, combustion involving just ALB samples will likely significantly reduce the operating costs. 


\title{
4. Conclusions and Summary
}

In this study, the slagging and fouling associated with underexploited biomass (TW and kenaf) before and after ash removal pretreatment was investigated. Ash removal pretreatment involved the neutralization of metal ions and carboxylic acids contained in the biomass ash. The primary findings of the study can be summarized as follows:

(1) XRF and ion chromatography revealed that ash removal pretreatment decreased the ash content produced by the three types of biomass, and the abundance of $\mathrm{Na}, \mathrm{Mg}, \mathrm{K}$, and $\mathrm{Cl}$, which are associated with clinker generation, decreased by $>80 \%$.

(2) DTF and gas analysis revealed that after mixing with $5 \%$ and $10 \%$ biomass, the NOx and UBC decreased, while SOx slightly increased. However, in most cases, the SOx values ranged between 30-50 ppm, which are lower than those for bituminous and sub-bituminous coal. Moreover, the NOx and SOx values for all samples decreased slightly, however, converged toward an error of approximately $10 \mathrm{ppm}$, while the UBC showed no trend.

(3) Ash deposition in the DTF, CE, and GRE was analyzed. Raw biomass exhibited a $\mathrm{V}$-shaped variation due to the presence of alkali contents in raw biomass. With ash removal pretreatment, these effects disappeared as CE and GRE gradually decreased.

In conclusion, ash removal pretreatment can be adopted to minimize slagging and fouling in a boiler, which will effectively eliminate internal corrosion and reduce the boiler operation cost. Additionally, the generation of fine particulate matter, representing another environmental issue, may also be decreased by the ALB technique.

Author Contributions: The manuscript was written through contributions of D.-G.L. as a first author; D.-G.L., M.-J.K., K.-H.K. and J.-S.K. designed and conducted the experiment; D.-G.L. and S.-M.K. analyzed the data; D.-G.L. performed validation writing; C.-H.J. is the corresponding author of this paper. All authors have read and agreed to the published version of the manuscript.

Funding: This research received no external funding.

Institutional Review Board Statement: Not applicable.

Informed Consent Statement: Not applicable.

Acknowledgments: This research was conducted under framework of the research and development program of The Korea Institute of Energy Research (C1-2428-01).

Conflicts of Interest: The authors declare no conflict of interest.

\author{
Abbreviations \\ ALB Ashless biomass, biomass from the ash removal process \\ DTF Drop Tube Furnace \\ WP Wood Pellet \\ TW Thinned Wood \\ UBC Unburned Carbon \\ CE Capture Efficiency \\ GRE Energy Based Growth Rate
}

\section{References}

1. WPAC Drax Biomass. 2016. Available online: https://www.pellet.org/wpac-agm/images/2016/Drax-Biomass---WPAC-2016--For-Sharing.pdf (accessed on 5 June 2020).

2. Data Basis Made with Natural Earth, AMI/LK/MIO. 2017. Available online: https:/ /www.ufop.de/ (accessed on 20 June 2019).

3. Islam, A.S.; Ahiduzzaman, M. Green electricity from rice husk. In A model for Bangladesh, Thermal Power Plants-Advanced Applications; Rasul, M., Ed.; IntechOpen: London, UK, 2013; pp. 127-144.

4. Qian, X.; Lee, S.; Chandrasekaran, R.; Yang, Y.; Caballes, M.; Alamu, O.; Chen, G. Electricity evaluation and emission characteristics of poultry litter co-combustion process. Appl. Sci. 2019, 9, 4116. [CrossRef]

5. Papilo, P.; Kusumanto, I.; Kunaifi, K. Assessment of agricultural biomass potential to electricity generation in Riau Province. IOP Conf. Ser. Earth Environ. Sci. 2017, 65, 012006. [CrossRef] 
6. Bryers, R.W. USA Fireside Slagging, Fouling, and High-Temperature Corrosion of Heat-Transfer Surface Due to Impurities in Steam-Raising Fuels. Prog. Energy Combust. Sci. 1996, 22, 29-120. [CrossRef]

7. Qian, X.; Xue, J.; Yang, Y.; Lee, S.W. Thermal properties and combustion-related problems prediction of agricultural crop residues. Energies 2021, 14, 4619. [CrossRef]

8. Niu, Y.; Tan, H. Ash-related issues during biomass combustion: Alkali-induced slagging, silicate melt-induced slagging (ash fusion), agglomeration, corrosion, ash utilization, and related countermeasures. Prog. Energy Combust. Sci. 2016, 52, 1-61. [CrossRef]

9. Lee, Y.; Park, J.; Song, G.; Namkung, H.; Park, S.; Kim, J.; Choi, J.; Jeon, C.; Choi, Y. Characterization of PM2.5 and Gaseous emissions during combustion of ultra-clean biomass via dual-stage treatment. Atmos. Environ. 2018, 193, 168-176. [CrossRef]

10. ASTM D3173/D3173M-17a. Standard Test Method for Moisture in the Analysis Sample of Coal and Coke; ASTM International: West Conshohocken, PA, USA, 2017.

11. ASTM D3175-20. Standard Test Method for Volatile Matter in the Analysis Sample of Coal and Coke; ASTM International: West Conshohocken, PA, USA, 2020.

12. ASTM D3172-13. Standard Test Method for Fixed Carbon in the Analysis Sample of Coal and Coke; ASTM International: West Conshohocken, PA, USA, 2017.

13. ASTM D3174-12(2018)e1. Standard Test Method for Ash in the Analysis Sample of Coal and Coke from Coal; ASTM International: West Conshohocken, PA, USA, 2018.

14. ASTM D5373-16. Standard Test Methods for Determination of Carbon, Hydrogen and Nitrogen in Analysis Samples of Coal and Carbon in Analysis Samples of Coal and Coke; ASTM International: West Conshohocken, PA, USA, 2016.

15. ASTM D5865-13. Standard Test Method for Gross Calorific Value of Coal and Coke; ASTM International: West Conshohocken, PA, USA, 2013.

16. Peng, B.; Wu, D.; Lai, J.; Xiao, H.; Li, P. Simultaneous determination of halogens (F, Cl, Br, and I) in coal using pyrohydrolysis combined with ion chromatography. Fuel 2012, 94, 629-631. [CrossRef]

17. Ballantyne, T.R.; Ashman, P.J.; Mullinger, P.J. A new method for determining the conversion of low-ash coals using synthetic ash as a tracer. Fuel 2005, 84, 1980-1985. [CrossRef]

18. Lourival, J.; Mendes, N.; Bazzo, E. Characterization and growth modeling of ash deposits in coal fired boilers. Powder Technol. 2012, 217, 61-68.

19. Standards Association of Australia Coal and Coke Analysis and Testing, Part 15: Higher Rank Coal Ash and Coke Ash Fusibility, 3rd ed.; Standards Australia: Homebush, NSW, Australia, 1995.

20. Rushdi, A.; Sharma, A.; Gupta, R. An experimental study of the effect of coal blending on ash deposition. Fuel 2004, 83, 495-506. [CrossRef]

21. Jeong, T.; Sh, L.; Kim, J.; Lee, B.; Jeon, C. Experimental investigation of ash deposit behavior during co-combustion of bituminous coal with wood pellets and empty fruit bunches. Energies 2019, 12, 2087. [CrossRef]

22. An, K.J.; Lee, B.H.; Kim, S.I.; Jeon, C.H. Study on slagging characteristic of hybrid coals using the thermo-mechanical analysis. In Proceedings of the Yeongheung Spring Conference on K.S.M.E., Yoengheung, Korea, 31 May 2013.

23. Blanchard, R. Measurements and Modeling of Coal Ash Deposition in an Entrained Flow Reactor. Master's Thesis, Brigham Young University, Provo, UT, USA, 2008.

24. Pudasainee, D.; Kim, J.H.; Lee, S.-H.; Park, J.-M.; Jang, H.-N.; Song, G.-J.; Seo, Y.-C. Hazardous air pollutants emission from coal and oil-fired power plants. Asia Pac. J. Chem. Eng. 2010, 5, 299-303. [CrossRef]

25. Li, S.; Xu, T.; Sun, P.; Zhou, Q.; Tan, H.; Hui, S. NOx and SOx emissions of a high sulfur self-retention coal during air-staged combustion. Fuel 2008, 87, 723-731. [CrossRef]

26. Jiang, Y.; Jeon, C. Comparative study on combustion and emission characteristics of torrefied and ashless biomass with coal through the $500 \mathrm{MW}$ tangentially fired boiler simulation. Energy Fuels 2021, 35, 561-574. [CrossRef]

27. Abreu, P.; Casaca, C.; Costa, M. Ash deposition during the co-firing of bituminous coal with pine sawdust and olive stones in a laboratory furnace. Fuel 2010, 89, 4040-4048. [CrossRef]

28. Kupka, T.; Mancini, M.; Irmer, M.; Weber, R. Investigation of ash deposit formation during co-firing of coal with sewage sludge, saw-dust and refuse derived fuel. Fuel 2008, 87, 2824-2837. [CrossRef] 